\title{
Radiation-Induced Lung Cancers in Murine Models
}

\author{
Leena Rivina1, Michael Davoren1" ${ }^{*}$, Robert H. Schiestl1,2,3,4 \\ ${ }^{1}$ Department of Environmental Health Sciences, University of California, Los Angeles, USA \\ ${ }^{2}$ Department of Pathology and Laboratory Medicine, University of California, Los Angeles, USA \\ ${ }^{3}$ Department of Radiation Oncology, University of California, Los Angeles, USA \\ ${ }^{4} \mathrm{JCCC}$ Healthy and At-Risk Populations Program Area, Los Angeles, USA \\ Email: mdavoren@ucla.edu, yelena.rivina@me.com, rschiestl@mednet.ucla.edu
}

Received 1 May 2014; revised 29 May 2014; accepted 5 June 2014

Copyright (C) 2014 by authors and Scientific Research Publishing Inc.

This work is licensed under the Creative Commons Attribution International License (CC BY).

http://creativecommons.org/licenses/by/4.0/

c) (i) Open Access

\section{Abstract}

Radiation therapy is a key weapon in the modern arsenal of cancer treatment. However, this effective treatment comes with risks of its own, and the sheer number of patients that undergo radiation as a part of their therapy regimen is only increasing. As this number increases, so does the incidence of secondary, radiation-induced neoplasias, creating a need for therapeutic agents targeted specifically towards reduction in the incidence of and treatment of these cancers. Development and efficacy testing of these agents requires not only extensive in vitro testing, but also a set of reliable animal models to accurately recreate the complex situations of radiation-induced carcinogenesis. The laboratory mouse Mus musculus remains the most relevant animal model in cancer research due to the molecular and physiological similarities it shares with man, its small size and high rate of breeding in captivity, and its fully sequenced genome. In this work, we review relevant $M$. musculus inbred and $F_{1}$ hybrid animal models, as well as methods of induction of radiation-induced lung cancers. Associated molecular pathologies are also included.

\section{Keywords}

Radiation Carcinogenesis, Animal Models, Radiation Protectors, Radiation Mitigators, Secondary Cancers

\section{Introduction}

As the population of the United States ages, cancer diagnosis rates continue to rise. At the same time, post-

${ }^{*}$ Corresponding author. 
therapy survival rates are increasing due to advances in medical technology. Current predictions suggest that roughly half of all US citizens will now be diagnosed with cancer at some point in their lifetimes, and of these a further half will receive radiation therapy as part of their treatment regimen [1]. Radiation can be administered as the sole avenue of palliative care, or more commonly in combination with other treatments such as chemotherapeutic drugs, molecular targeted therapy, or immunotherapy. The power and utility of radiation as a therapeutic tool, however, comes at a cost. The exposure of healthy tissue to radiation as collateral damage from radiotherapy can result in a variety of acute toxicities or chronic secondary malignancies, and specifically radiation-induced cancer [2].

Rapid technological advances in radiation oncology have provided a greater degree of targeted radiation delivery to tumor sites, reducing unnecessary exposure of healthy surrounding tissues. This more accurate delivery of radiation has the benefit of increasing maximum tolerated doses and increasing the therapeutic ratio [3] [4]. Unfortunately, the very nature of tumor growth and complex tumor/healthy tissue interaction makes it infeasible to completely avoid all collateral exposure, and therefore all potential subsequent malignancy. This fact calls for the development of alternative biological therapies to supplement technological solutions, in order to reduce secondary toxicity and malignancy risks to the absolute minimum.

Three potential classes of agents could be applied in order to modulate damage to normal tissue. The first class, radiation protectors, consists of agents given prior to radiation exposure. The second, radiation mitigators, would be given post-exposure (PE), but prior to the onset of symptoms; while the third, therapies, would be administered after the onset of symptoms [5]. Only one agent, amifostine [6], is currently approved by the Food and Drug Administration (FDA) to protect normal tissues during irradiation. Amifostine falls only under the first category, with intravenous administration generally occurring a few minutes prior to radiotherapy. The government and medical research community recognize that this single therapy is not sufficient. In order to meet this need, the National Cancer Institute (NCI), in collaboration with National Institute of Allergy and Infectious Diseases (NIAID) has proposed an algorithm to be used in the selection of agents for preclinical and clinical development aimed at decreasing the adverse effects of cancer therapy, including radiation [7]. The use of animal models to validate these agents is a key part of meeting the requirements of this algorithm. Therefore, a comprehensive description of the animal models relevant to the adverse affects of radiotherapy is of great utility to researchers in the field of prospective treatment development. Williams and colleagues have already extensively covered the selection of animal models designed to mitigate and treat the more acute toxicities associated with radiation exposure [8]. The purpose of this work is to provide an updated review of select inbred mouse models for radiation induced lung cancer, that may be used in preclinical settings in order to test the efficacy of agents specifically intended to protect, mitigate or treat radiation-induced carcinogenesis.

\section{Methods}

\subsection{Research Strategy}

As a mammalian species with a short maturation time, the laboratory mouse, Mus musculus, is one of the best models available for the study of carcinogenesis and its corresponding pathologies. Over time the laboratory mouse has undergone a significant evolution in its complexity. As researchers continue to delve into its genome and develop precise techniques to manipulate it, it has gained the ability to mimic progressively more precise aspects of the multifaceted disease that is cancer. The modern researcher's arsenal contains murine models that range from specific carcinogen-inducible tumors, to xenograft models fully compatible with human neoplastic cells, to humanized mice expressing human genes. Genetically Engineered Mice (GEM) have now been imbued with the ability to accurately recapitulate the pathophysiological and underlining molecular features of many human cancers [9]. As a result, GEM have replaced many of the genetically homogenous inbred mice once used in environmentally induced cancer studies. With respect to their genetically engineered relatives, older models often developed tumors at low frequencies and with variable latencies. However, GEM specific to a particular question of carcinogenesis are often still difficult to come by, overly expensive, or have not yet been described to an adequate extent. In addition, as GEM are characteristically designed to follow an exact carcinogenesis progression path, their use precludes the study of alternative mechanisms. For these reasons, the use of inbred strains remains a cornerstone of in vivo cancer research. Despite their flaws, inbred mice have been indispensible in the discoveries of oncogenes and tumor suppressors, as well as preclinical assessment of the toxic or therapeutic effects of countless agents [10], discoveries critical to the development and validation of GEM. 
In this review, we set out to identify inbred mouse models of radiation-induced (RI) lung cancers, intended for assessment of efficacy towards interventions aimed at protecting, mitigating or treating these malignancies. We have concentrated on models specific to lung, cancer as this subtype has been identified as the most common secondary cancer arising post radiation therapy [2].

\subsection{Inclusion Criteria}

The scope of this review is limited to murine models of radiation-induced lung carcinogenesis. It is specifically focused on those cancers designed to induce following exposures to low-LET gamma- and X-ray radiations using both high total dose and high dose-rate. Carcinogenesis induced from high-LET radiation, genetically engineered mouse models, and xenograft models are outside of the scope of this work. For the most part, we have also excluded models requiring supplemental treatment in addition to radiation in order to induce carcinogenesis. Only inbred mice with cancer inducible by either a single total body irradiation (TBI) or fractionated targeted exposures are described. In order to maximize clinical relevance, we have chosen to focus only on murine models that tightly mimic the underlying molecular pathologies of each type of cancer as observed in humans.

\section{Results and Discussion}

\subsection{Radiation-Induced Lung Cancer}

Lung carcinoma is the deadliest cancer in industrialized nations, responsible for over a quarter of all cancer deaths. The majority of lung cancer cases can be attributed to smoking [11]. At the same time, lung carcinomas were one of the first radiation-associated cancers to be identified, due to their high rate of mortality [12]. Three groups have been historically responsible for the majority of data on the contribution of radiation exposure to lung carcinogenesis. These groups are 1) underground miners, exposed to internal alpha radiation via radon-222 and radon-220 inhalation; 2) Patients who have undergone radiotherapy patients to treat neoplastic and nonneoplastic malignancies, and 3) Japanese atomic bomb survivors [13]-[15]. The latency period for gamma and X-ray exposed individuals seems to be a minimum of 9 - 10 years, with an increased risk persisting in survivors for over 25 years. After correcting for the confounding factor of smoking rates, females are considerably more susceptible to radiation-induced lung cancer than males. Judging from Japanese survivor data, adenocarcinoma appears to be the most common type of lung cancer in an exposed population. No correlation exists between age of exposure and development of malignancy [14] [16] [17]. Travis and colleagues have reported that Hodgkin's disease patients treated with radiation doses of $40 \mathrm{~Gy}$ or more exhibit a significant increase in all histopathological types of lung cancer, after controlling for smoking. Incidence of these secondary lung cancers in IR-treated Hodgkin's Disease patients peaks at 5 - 9 years following radiation therapy [18]-[20]. Evidence of a lung cancer-IR link is further supported by studies reporting increased rates of lung cancer in IR-treated breast cancer survivors [21] [22].

The consequences of radiation exposure, shared by both mice and humans, include pulmonary fibrosis and carcinogenesis. Whether an exposure to radiation will result in primarily pulmonary fibrosis or increased cancer risk appears to be a function of dose, with a much smaller dose required for initiation of carcinogenesis [23]. A report authored by Williams et al. provides an extensive guide for the selection of radiation induced fibrosis animals models, as well as models of other radiation-induced malignancies [8]. Table 1 below summarizes three models of radiation-induced lung cancer, generated employing whole body irradiations and targeted thoracic exposures in $\mathrm{C} 3 \mathrm{H}, \mathrm{BALB} / \mathrm{c}$ and RF mice.

Table 1. Induction of lung cancer in mice with low-LET ionizing radiation.

\begin{tabular}{|c|c|c|c|c|c|c|c|c|}
\hline Mouse Strain & Age & Sex & Dosage & Fractionation & Latency & $\begin{array}{c}\text { Spontaneous } \\
\text { Frequency }\end{array}$ & $\begin{array}{c}\text { Induced } \\
\text { Frequency }\end{array}$ & Ref. \\
\hline C3H (C3H/HeSlc) & 6 weeks & M & $\begin{array}{l}7.5 \text { Gy, } \\
\text { thorax }\end{array}$ & 2 doses, 12-hour interval & 12 months & $3.5 \%-9.5 \%$ & $40 \%$ & $\begin{array}{l}{[25]} \\
{[27]}\end{array}$ \\
\hline RFM (RFM/Un) & 10-12 weeks & $\mathrm{F}$ & $\begin{array}{l}9 \mathrm{~Gy}, \\
\text { thorax }\end{array}$ & single & 9 months & $\sim 28 \%$ & $87 \%$ & $\begin{array}{l}{[29]} \\
{[30]}\end{array}$ \\
\hline BALB/c (BALB/c/An) & 12 weeks & $\mathrm{F}$ & 2 Gy TBI & single & 12 months & $\sim 12 \%$ & $\sim 37 \%$ & $\begin{array}{l}{[31]} \\
{[42]}\end{array}$ \\
\hline
\end{tabular}




\subsection{C3H Mouse}

$\mathrm{C} 3 \mathrm{H} / \mathrm{He}$ mice are moderately sensitive to the induction of lung cancers via IR, and develop spontaneous lung tumors at a low frequency [24]. A regimen consisting of a single 7.5 Gy irradiation to the thorax followed by three 3 Gy whole body irradiations at 3-month intervals afterward yields the highest induction frequency at 62\%. However, this protracted irradiation program is of potentially little relevance to human exposure scenarios. A scheme of two 7.5 Gy thoracic irradiations with a 12-hour interval is far more clinically relevant, and yields roughly $40 \%$ induction in males exposed at 6 weeks of age. These mice tend to develop alveologenic adenomas and adenocarcinomas after a latency period of 12 months. Tubular- or papillary-form tumors are only rarely observed [25]. In a series of dose response studies utilizing a single whole body dose of irradiation, Hashimoto and colleagues showed that tumor incidence increased with dose to a peak at 5.0 Gy, but decreased at $10 \mathrm{~Gy}$. This demonstrates the previously discussed competitive dynamics between opposing cancer inductive and suppressive effects of radiation [26].

Other factors play a role in tumor induction, including those as ostensibly disparate as circadian rhythm. An irradiation at night is a far more potent inducer of RI-LT in C3H mice than an equivalent daytime dose. A full 5 Gy of irradiation during the day is required to match the tumor induction frequency seen with just 1.25 Gy at night [25]. Diurnal variations have been reported in human cancer therapy response as well [27]. The C3H mouse appears to be the optimal choice IR-LC studies with its low spontaneous and moderate induction frequencies. Coggle and colleagues suggest that induction with thoracic irradiations be the preferred method for this strain [23] due to clinical relevance and reduced induction of other tumors in the animal, that could contribute to lethality or obfuscate a lung cancer centered investigation.

\subsection{RF Mouse}

Lung adenoma is inducible in both male and female RFM/Un mice when they are exposed to IR at 10 - 12 weeks old [28] [29]. Following a single 9.0 Gy thoracic irradiation roughly $87 \%$ of females develop lung cancer within 6 - 9 months, with an average of 1.8 tumors per mouse. Males are slightly more resilient, requiring a dose of 10.0 Gy to develop the same malignancy roughly $54 \%$ of the time within 11 months, with a tumor multiplicity of 0.8 tumors per mouse. Both genders of this strain exhibit a relatively high incidence of spontaneous carcinogenesis, developing in $28 \%$ of females and $32 \%$ of males [28] [29].

\subsection{BALB/C Mouse}

A single 2.0 Gy whole body irradiation at a high dose rate $(0.35 \mathrm{~Gy} / \mathrm{min})$ administered to a 12 -week-old female $\mathrm{BALB} / \mathrm{c} / \mathrm{An}$ mouse results in a $37 \%$ induction rate of lung adenocarcinoma. It takes roughly a year before the cancer becomes apparent. The spontaneous rate of these mice developing this cancer is between 11\% - 14\% [30]. Fractionation of the 2.0 Gy dose at a low rate of exposure dose does not increase lung cancer incidence relative to the single irradiation [31].

\subsection{Lung Cancer-Associated Molecular Pathologies}

The effects of dose, dose-rate, fractionation and radiation quality on murine lung carcinogenesis have been studied extensively for some time. However, the mechanisms of lung cancer induction are notoriously difficult to discern in animal models. The underlying molecular and pathophysiological mechanisms largely remained elusive until the emergence of genetically engineered mouse models. Furthermore, these molecular mechanisms have yet to be definitively correlated to the observed pathologies in inbred strains [12] [26] [28] [29] [31] [32]. Some data have been retroactively extrapolated from massive radiation studies involving 40,000 B6CF hybrid mice (C57BL/6 females × BALB/c male) at Argonne National Laboratory from 1971-1986 [33] [34]. Genetic material was extracted for PCR-amplification from the paraffin-preserved lung tissues of animals with adenocarcinomas and controls. A significant percentage of the samples derived from radiation-induced or spontaneous lung adenocarcinomas show deletions of the tumor suppressor $R b$. There were no statistically significant differences in $R b$ deletion frequency observed between adenocarcinomas from animals thatreceived 60 weekly doses of $0.1 \mathrm{~Gy}$, spontaneously developed adenocarcinomas, and those from animals exposed to single-doses of 5.69 Gy. Zhang and Woloschack reported that $97 \%$ of samples containing $R b$ deletions also carried $p 53$ deletions, and concluded that the mutation of $p 53$ was likely a predominant step in radiation-induced lung carcinogenesis 


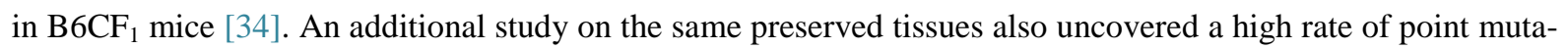
tions in the K-ras gene in both spontaneously derived cancers and neoplastic samples resulting from 24 or 60 once-weekly irradiations [35].

Murine lung cancers share multiple salient features with human lung tumors, with alterations in $p 53, K$-ras, and $R b$ commonly observed in both [36]-[38]. The $p 53$ tumor suppressor, popularly dubbed the "guardian of the genome" is inactivated by either deletion or mutation in $80 \%$ of primary lung tumors [39]-[42]. Its loss is associated with poor clinical outcome [38]. The retinoblastoma protein $(R b)$ is another tumor suppressor either directly or indirectly inactivated in a wide variety of tumors, including $90 \%$ of human small cell carcinomas [43] [44]. K-ras, the proto-oncogene involved in cell differentiation, growth, and apoptosis [32], is also widely modified in cancers. $20 \%$ - 30\% of human lung adenocarcinomas possess a mutation in the KRAS gene [45]. Activated $K$-ras is also associated with a poor clinical prognosis [46].

The use of inbred models is particularly valuable for the testing of therapeutic agents directed against secondary cancers, including those induced or promoted by radiation therapy. Mice genetically engineered to mimic human cancers, such as mice with K-ras knockout of lung adenocarcinoma [9], are useful and sophisticated models, but are self-limiting and biased by their purposefully designed natures. As these models are predisposed to develop only one type of malignancy along a designated progression route, they do not permit the study of alternative mechanisms of carcinogenesis. If radiation-induced lung carcinogenesis does not precisely follow the pre-programmed initiation and progression pathways, then the studies using GEM are not of general use, and therapies based on these models will not necessarily be effective in a human. Inbred mice, however, present an unbiased approach to discovery studies.

\section{Conclusions}

The ideal radiation-induced carcinogenesis mouse model possesses a low spontaneous background frequency of the desired malignancy, has a short latency period, avoids co-developing cancers at alternative sites, and produces tumors nearly identical to the corresponding human cancer in onset, progression and underlying pathology. As a perfect model does not exist, researchers are inevitably forced to compromise on some of these features. It is generally more feasible to compromise on features such as cancer latency and induction frequency, as these can be compensated for by study design and sheer subject volume. However, one cannot compromise on the accurate emulation of molecular and pathophysiological features of human radiation-induced malignancies, as these are the features that make a model relevant in the first place. More advances must be made towards the development of more accurate recapitulations of human radiation-induced cancers. Radiation-induced secondary cancers can still be difficult to discern from primary tumors in humans due to unresolved questions about their respective molecular signatures. Identifying and investigating these signatures in mouse tumors following IR is a difficult challenge with great potential rewards.

The mouse models presented are often a compromise on the background frequencies and rates of induction, but all demonstrate strong molecular and phenotypic correlations to salient features of the human cancers they are meant to represent. These models provide a powerful tool for testing the therapeutic benefit of candidate drugs against radiation-induced carcinogenesis.

\section{Conflicts of Interest}

The authors declare no conflict of interest.

\section{Acknowledgements}

The authors wish to thank the NIEHS Training Grant in Molecular Toxicology for funding provided to Michael Davoren. We would like to acknowledge for funding provided by NIH CMCR Grant No. 1 U19 A1 67769-01.

\section{References}

[1] Howlader, N., Noone, A.M., Krapcho, M., Neyman, N., Aminou, R., Altekruse, S.F., Kosary, C.L., Ruhl, J., Tatalovich, Z., Cho, H., Mariotto, A., Eisner, M.P., Lewis, D.R., Chen, H.S., Feuer, E.J. and Cronin, K.A. (2012) SEER Cancer Statistics Review, 1975-2009 (Vintage 2009 Populations). National Cancer Institute, Bethesda.

[2] Hall, E.J. and Giaccia, A.J. (2012) Radiobiology for the Radiologist. 7th Edition, Wolters Kluwer Health/Lippincott 
Williams \& Wilkins, Philadelphia.

[3] de Arruda, F.F., Puri, D.R., Zhung, J., Narayana, A., Wolden, S., Hunt, M., Stambuk, H., Pfister, D., Kraus, D., Shaha, A., et al. (2006) Intensity-Modulated Radiation Therapy for the Treatment of Oropharyngeal Carcinoma: The Memorial Sloan-Kettering Cancer Center Experience. International Journal of Radiation Oncology, Biology, Physics, 64, 363-373. http://dx.doi.org/10.1016/j.ijrobp.2005.03.006

[4] Zelefsky, M.J., Fuks, Z. and Leibel, S.A. (2002) Intensity-Modulated Radiation Therapy for Prostate Cancer. Seminars in Radiation Oncology, 12, 229-237. http://dx.doi.org/10.1053/srao.2002.00000

[5] Kim, K., Damoiseaux, R., Norris, A.J., Rivina, L., Bradley, K., Jung, M.E., Gatti, R.A., Schiestl, R.H. and McBride, W.H. (2011) High Throughput Screening of Small Molecule Libraries for Modifiers of Radiation Responses. International Journal of Radiation Biology, 87, 839-845. http://dx.doi.org/10.3109/09553002.2011.560994

[6] Rubin, P. (2008) Late Effects of Cancer Treatment on Normal Tissues: CURED I, LENT. Springer, Berlin, New York. http://dx.doi.org/10.1007/978-3-540-49070-8

[7] Ryan, J.L., Krishnan, S., Movsas, B., Coleman, C.N., Vikram, B. and Yoo, S.S. (2011) Decreasing the Adverse Effects of Cancer Therapy: An NCI Workshop on the Preclinical Development of Radiation Injury Mitigators/Protectors. Radiation Research, 176, 688-691. http://dx.doi.org/10.1667/RR2704.1

[8] Williams, J.P., Brown, S.L., Georges, G.E., Hauer-Jensen, M., Hill, R.P., Huser, A.K., Kirsch, D.G., Macvittie, T.J., Mason, K.A., Medhora, M.M., et al. (2010) Animal Models for Medical Countermeasures to Radiation Exposure. Radiation Research, 173, 557-578. http://dx.doi.org/10.1667/RR1880.1

[9] Jackson, E.L., Willis, N., Mercer, K., Bronson, R.T., Crowley, D., Montoya, R., Jacks, T. and Tuveson, D.A. (2001) Analysis of Lung Tumor Initiation and Progression Using Conditional Expression of Oncogenic K-Ras. Genes \& Development, 15, 3243-3248. http://dx.doi.org/10.1101/gad.943001

[10] Frese, K.K. and Tuveson, D.A. (2007) Maximizing Mouse Cancer Models. Nature Reviews Cancer, 7, 645-658. http://dx.doi.org/10.1038/nrc2192

[11] Carbone, D. (1992) Smoking and Cancer. The American Journal of Medicine, 93, 13S-17S. http://dx.doi.org/10.1016/0002-9343(92)90621-h

[12] Coggle, J.E. (1991) The Role of Animal Models in Radiation Lung Carcinogenesis. Radiation and Environmental Biophysics, 30, 239-241. http://dx.doi.org/10.1007/BF01226628

[13] Darby, S.C., Doll, R., Gill, S.K. and Smith, P.G. (1987) Long Term Mortality after a Single Treatment Course with X-Rays in Patients Treated for Ankylosing Spondylitis. British Journal of Cancer, 55, 179-190. http://dx.doi.org/10.1038/bjc.1987.35

[14] Fajardo, L.F., Berthrong, M. and Anderson, R.E. (2001) Radiation Pathology. Oxford University Press, New York.

[15] Griem, M.L., Kleinerman, R.A., Boice Jr., J.D., Stovall, M., Shefner, D. and Lubin, J.H. (1994) Cancer Following Radiotherapy for Peptic Ulcer. Journal of the National Cancer Institute, 86, 842-849. http://dx.doi.org/10.1093/jnci/86.11.842

[16] Egawa, H., Furukawa, K., Preston, D., Funamoto, S., Yonehara, S., Matsuo, T., Tokuoka, S., Suyama, A., Ozasa, K., Kodama, K., et al. (2012) Radiation and Smoking Effects on Lung Cancer Incidence by Histological Types among Atomic Bomb Survivors. Radiation Research, 178, 191-201. http://dx.doi.org/10.1667/RR2819.1

[17] Preston, D.L., Ron, E., Tokuoka, S., Funamoto, S., Nishi, N., Soda, M., Mabuchi, K. and Kodama, K. (2007) Solid Cancer Incidence in Atomic Bomb Survivors: 1958-1998. Radiation Research, 168, 1-64. http://dx.doi.org/10.1667/RR0763.1

[18] Travis, L.B. (2002) Therapy-Associated Solid Tumors. Acta Oncologica, 41, 323-333. http://dx.doi.org/10.1080/028418602760169361

[19] Travis, L.B., Curtis, R.E. and Boice Jr., J.D. (1996) Late Effects of Treatment for Childhood Hodgkin's Disease. The New England Journal of Medicine, 335, 352-353. http://dx.doi.org/10.1056/NEJM199608013350515

[20] Travis, L.B., Gospodarowicz, M., Curtis, R.E., Clarke, E.A., Andersson, M., Glimelius, B., Joensuu, T., Lynch, C.F., van Leeuwen, F.E., Holowaty, E., et al. (2002) Lung Cancer Following Chemotherapy and Radiotherapy for Hodgkin's Disease. Journal of the National Cancer Institute, 94, 182-192. http://dx.doi.org/10.1093/jnci/94.3.182

[21] Kirova, Y.M., Gambotti, L., De Rycke, Y., Vilcoq, J.R., Asselain, B. and Fourquet, A. (2007) Risk of Second Malignancies after Adjuvant Radiotherapy for Breast Cancer: A Large-Scale, Single-Institution Review. International Journal of Radiation Oncology, Biology, Physics, 68, 359-363. http://dx.doi.org/10.1016/j.ijrobp.2006.12.011

[22] Prochazka, M., Granath, F., Ekbom, A., Shields, P.G. and Hall, P. (2002) Lung Cancer Risks in Women with Previous Breast Cancer. European Journal of Cancer, 38, 1520-1525. http://dx.doi.org/10.1016/S0959-8049(02)00089-8

[23] Coggle, J.E., Lambert, B.E. and Moores, S.R. (1986) Radiation Effects in the Lung. Environmental Health Perspectives, 70, 261-291. http://dx.doi.org/10.1289/ehp.8670261 
[24] Endoh, D., Suzuki, A., Kuwabara, M., Satoh, H. and Sato, F. (1987) Circadian Variation in Lung Tumor Induction with X-Rays in Mice. Journal of Radiation Research, 28, 186-189. http://dx.doi.org/10.1269/jrr.28.186

[25] Hashimoto, N., Endoh, D., Kuwabara, M., Satoh, H. and Sato, F. (1994) Induction of Lung Tumors in C3H Strain Mice after Single or Fractionated Irradiation with X-Rays. The Journal of Veterinary Medical Science/The Japanese Society of Veterinary Science, 56, 493-498. http://dx.doi.org/10.1292/jvms.56.493

[26] Hashimoto, N., Endoh, D., Kuwabara, M., Satoh, H. and Sato, F. (1990) Dose and Dose-Splitting Effects of X-Rays on Lung Tumour Induction in Mice. International Journal of Radiation Biology, 58, 351-360. http://dx.doi.org/10.1080/09553009014551681

[27] Focan, C. (2002) Chronobiological Concepts Underlying the Chronotherapy of Human Lung Cancer. Chronobiology International, 19, 253-273. http://dx.doi.org/10.1081/CBI-120002601

[28] Ullrich, R.L., Jernigan, M.C. and Adams, L.M. (1979) Induction of Lung Tumors in RFM Mice after Localized Exposures to X Rays or Neutrons. Radiation Research, 80, 464-473. http://dx.doi.org/10.2307/3574988

[29] Yuhas, J.M. and Walker, A.E. (1973) Exposure-Response Curve for Radiation-Induced Lung Tumors in the Mouse. Radiation Research, 54, 261-273. http://dx.doi.org/10.2307/3573704

[30] Ullrich, R.L. (1983) Tumor Induction in BALB/c Female Mice after Fission Neutron or Gamma Irradiation. Radiation Research, 93, 506-515. http://dx.doi.org/10.2307/3576029

[31] Ullrich, R.L., Jernigan, M.C., Satterfield, L.C. and Bowles, N.D. (1987) Radiation Carcinogenesis: Time-Dose Relationships. Radiation Research, 111, 179-184. http://dx.doi.org/10.2307/3577031

[32] Vojtek, A.B. and Der, C.J. (1998) Increasing Complexity of the Ras Signaling Pathway. The Journal of Biological Chemistry, 273, 19925-19928. http://dx.doi.org/10.1074/jbc.273.32.19925

[33] Grahn, D., Lombard, L.S. and Carnes, B.A. (1992) The Comparative Tumorigenic Effects of Fission Neutrons and Cobalt-60 Gamma Rays in the B6CF1 Mouse. Radiation Research, 129, 19-36. http://dx.doi.org/10.2307/3577899

[34] Zhang, Y. and Woloschak, G.E. (1997) Rb and p53 Gene Deletions in Lung Adenocarcinomas from Irradiated and Control Mice. Radiation Research, 148, 81-89. http://dx.doi.org/10.2307/3579541

[35] Zhang, Y. and Woloschak, G.E. (1998) Detection of Codon 12 Point Mutations of the K-Ras Gene from Mouse Lung Adenocarcinoma by “Enriched” PCR. International Journal of Radiation Biology, 74, 43-51. http://dx.doi.org/10.1080/095530098141717

[36] Salgia, R. and Skarin, A.T. (1998) Molecular Abnormalities in Lung Cancer. Journal of Clinical Oncology: Official Journal of the American Society of Clinical Oncology, 16, 1207-1217.

[37] Sekido, Y., Fong, K.M. and Minna, J.D. (1998) Progress in Understanding the Molecular Pathogenesis of Human Lung Cancer. Biochimica et Biophysica Acta, 1378, F21-F59.

[38] Tuveson, D.A. and Jacks, T. (1999) Modeling Human Lung Cancer in Mice: Similarities and Shortcomings. Oncogene, 18, 5318-5324. http://dx.doi.org/10.1038/sj.onc.1203107

[39] D’Amico, D., Carbone, D., Mitsudomi, T., Nau, M., Fedorko, J., Russell, E., Johnson, B., Buchhagen, D., Bodner, S., Phelps, R., et al. (1992) High Frequency of Somatically Acquired p53 Mutations in Small-Cell Lung Cancer Cell Lines and Tumors. Oncogene, 7, 339-346.

[40] Hensel, C.H., Xiang, R.H., Sakaguchi, A.Y. and Naylor, S.L. (1991) Use of the Single Strand Conformation Polymorphism Technique and PCR to Detect p53 Gene Mutations in Small Cell Lung Cancer. Oncogene, 6, 1067-1071.

[41] Sameshima, Y., Matsuno, Y., Hirohashi, S., Shimosato, Y., Mizoguchi, H., Sugimura, T., Terada, M. and Yokota, J. (1992) Alterations of the p53 Gene Are Common and Critical Events for the Maintenance of Malignant Phenotypes in Small-Cell Lung Carcinoma. Oncogene, 7, 451-457.

[42] Takahashi, T., Takahashi, T., Suzuki, H., Hida, T., Sekido, Y., Ariyoshi, Y. and Ueda, R. (1991) The p53 Gene Is Very Frequently Mutated in Small-Cell Lung Cancer with a Distinct Nucleotide Substitution Pattern. Oncogene, 6, 17751778.

[43] Olsson, A.Y., Feber, A., Edwards, S., Te Poele, R., Giddings, I., Merson, S. and Cooper, C.S. (2007) Role of E2F3 Expression in Modulating Cellular Proliferation Rate in Human Bladder and Prostate Cancer Cells. Oncogene, 26, 1028-1037. http://dx.doi.org/10.1038/sj.onc.1209854

[44] Sherr, C.J. and McCormick, F. (2002) The RB and p53 Pathways in Cancer. Cancer Cell, 2, 103-112. http://dx.doi.org/10.1016/S1535-6108(02)00102-2

[45] Califano, R., Landi, L. and Cappuzzo, F. (2012) Prognostic and Predictive Value of K-RAS Mutations in Non-Small Cell Lung Cancer. Drugs, 72, 28-36. http://dx.doi.org/10.2165/1163012-S0-000000000-00000

[46] Bongiorno, P.F., Whyte, R.I., Lesser, E.J., Moore, J.H., Orringer, M.B. and Beer, D.G. (1994) Alterations of K-Ras, p53, and erbB-2/neu in Human Lung Adenocarcinomas. The Journal of Thoracic and Cardiovascular Surgery, 107, 590-595. 